\title{
Do papel atribuído ao papel exercido: a política de formação continuada de alfabetizadores em municípios cearenses*
}

\author{
From the assigned to the played role: literacy \\ teacher continuing education in municipalities of \\ the state of Ceará
}

\section{Del papel atribuido al papel ejercido: la política de formación continua de alfabetizadores en municipios del estado de Ceará}

\author{
Clotenir Damasceno Rabelo** \\ Alda Maria Duarte Araújo Castro***
}

Resumo: Este artigo aborda o papel exercido pelos municípios nas políticas de formação continuada de alfabetizadores. Trata-se de uma pesquisa realizada em Municípios cearenses, tendo como recorte contextual o período de 2003 a 2006. O exame traz a noção de relações intergovernamentais e mecanismos cooperativos como ferramentas teórico-centrais e, por meio de etapas inter-relacionadas de análise bibliográfica e documental e de trabalho de campo, procede a análise da inter-relação das políticas municipais e as políticas elaboradas pelo Governo Federal e/ou Estadual para a formação continuada de alfabetizadores. A pesquisa revela que, no plano das realidades pesquisadas, cuidar das políticas de formação continuada dos alfabetizadores não é papel municipal exclusivo, mas competência comum aos entes federados, no âmbito do federalismo cooperativo brasileiro.

Palavras-chave: Relações intergovernamentais. Políticas de formação continuada de alfabetizadores. Papel do município.

\footnotetext{
Abstract: The paper is about the role played by the municipalities in the literacy teacher continuing education policies. It is a research conducted in Ceará municipalities, Brazil, having the period between 2003 and 2006 as a contextual sample. The study brings the notion of intergovernmental relations and cooperative mechanisms as theoretical

* Trabalho relativo à pesquisa concluída para tese de doutoramento, com apoio do CNPq (Conselho Nacional de Desenvolvimento Científico e Tecnológico), orientado pela Prof ${ }^{a} \operatorname{Dr}^{a}$ Alda Maria Duarte Araújo Castro.

** Coordenador pedagógico da Secretaria Municipal da Educação - Icapuí - CE. Email: <clotenirdr@gmail. com>

*** Professora da Universidade Federal do Rio Grande do Norte (UFRN). Email: <alda@ufrnet.br>
} 
and central tools and, through interrelated stages of bibliographical and document analysis as well as fieldwork, it is carried out the analysis of the interrelation between the municipal policies and the policies developed by the Federal and/or State Government for literacy teacher continuing education. The research reveals that in the field of the realities examined taking care of the literacy teacher continuing education policies is not an exclusive municipal role, but it is a common competence of the federated entities within the Brazilian cooperative federalism.

Keywords: Intergovernmental relations. Literacy teacher continuing education policies. Role of the municipality.

Resumen: El artículo aborda el papel ejercido por los municipios en las políticas de formación continua de alfabetizadores. Se trata de una investigación realizada en municipios del estado de Ceará, teniendo como muestra contextual el período comprendido entre 2003 y 2006. El estudio trae la noción de relaciones intergubernamentales y mecanismos cooperativos como herramientas teórico centrales y, por medio de etapas interrelacionadas de análisis bibliográfico y documental y de trabajo de campo, efectúa el análisis de la interrelación de las políticas municipales y las políticas elaboradas por el Gobierno Federal y/o Estatal para la formación continua de alfabetizadores. La investigación revela que, en el plano de las realidades estudiadas, ocuparse de las políticas de formación continua de los alfabetizadores no es papel exclusivo de los municipios, pero competencia común a los entes federados, en el ámbito del federalismo cooperativo brasileño.

Palabras clave: Relaciones intergubernamentales. Políticas de formación continua de alfabetizadores. Papel del municipio.

\section{Introdução}

Este trabalho constitui uma parcela de elaboração do conhecimento em torno da redescoberta do Município como novo integrante na constituição das políticas educacionais, no plano da maior precisão do perfil federativo educacional brasileiro e suas consequentes relações de colaboração e assimetria entre os entes federados nessa dimensão.

A proposição de pesquisar tal matéria, no escopo deste estudo, consiste em realizar essa verificação - considerando as iniciativas federais para a formação continuada de alfabetizadores - nos anos entre a finalização do Profa (Programa de Formação de Alfabetizadores) em 2002 com o encerramento da "era FHC" e a formatação e a implantação da política educacional do primeiro Governo Lula, nos idos de 2003 a 2006 no plano federal. De acordo com Azevedo (2011), nesse 
período, por meio da coalização que assumiu o Governo brasileiro, em 2003, aprofundaram-se as relações de colaboração entre a União e os municípios, em especial, por meio da expansão e/ou modificação de programas e projetos criados no governo anterior.

Tomando como ponto de partida essa ideia, trabalha-se com o pressuposto de que os municípios assumem, atualmente, distintas relações com outras esferas administrativas, em especial, a União, na configuração de seu papel no campo educacional. No que se refere às políticas de formação continuada de alfabetizadores, importa compreender se os municípios tomam para si, sob uma diversidade de princípios, dispositivos e processos, o papel de formulação, implementação e execução de iniciativas/políticas de formação continuada de alfabetizadores, cuidando dessa tarefa em nível local.

O presente artigo, em particular, é uma constatação dos resultados da investigação sobre o papel dos municípios nas políticas de formação continuada de alfabetizadores, abordando, em sua primeira seção, as determinações teórico-práticas que compõem a compreensão do papel municipal na formulação e implementação de políticas educacionais. Traz, de forma articulada, o corpo teórico do estudo, em temáticas como "relações intergovernamentais" (RIG’s) e "mecanismos cooperativos", tidas como ferramentas teóricas centrais e como bases federativas na formulação e execução de políticas de educação.

Na segunda seção, discute as relações entre Estado e municípios no Estado do Ceará, as práticas descentralizadoras e colaborativas e o papel exercido nas políticas de formação continuada de alfabetizadores no Estado, as características das políticas e gestão da educação, no período de 2003 a 2006, à luz dos documentos oficiais, considerando as práticas de municipalização desenvolvidas na condução da política educacional desse Estado, e tendo, como pano de fundo, suas especificidades históricas.

A terceira seção discute o papel exercido pelos municípios pesquisados e as ações efetivadas, seja por iniciativa interna ou por meio de colaboração com os demais entes federados para a gestão da educação e, sobretudo, para a formação continuada dos alfabetizadores, revelando suas práticas específicas e assimetrias.

\section{Federalismo e as relações intergovernamentais: aportes teóricos}

No campo da política educacional, a discussão das relações intergovernamentais e da tarefa municipal não se expressa como temática recorrente; no entanto, segundo Cury (2012), o bom desempenho da interação dos entes federados brasileiros é condição sine qua non para abranger a sonhada atribuição coletiva de gerenciar um Sistema Nacional de Educação amplo e democrático. Nessa perspectiva, as 
relações intergovernamentais constituem, pois, assunto relevante para a análise do significado dessa interação, em especial do significado do município nas políticas educacionais, de sua formulação e execução.

A diversidade de arranjos federativos ocasionados pelos modos distintos com que cada Federação vivencia os princípios políticos do federalismo determina a variação de graus de autonomias das unidades entre si e a variação de mecanismos relacionais entre as unidades constitutivas desse arranjo (COSTA, 2010). Mesmo considerando essa variedade, entre os cinco aspectos comuns que integram o universo federativo, segundo Abrucio (2001), a dinâmica das relações intergovernamentais expressa em práticas de cooperação e competição, situam-se como chaves que, bem combinadas, promovem boa coordenação federativa, e como instrumento útil para a produção e delimitação das funções governamentais, estabelecendo a atuação das unidades por meio de decisões compartilhadas. Por essa razão, é valioso, para esse estudo, validar o uso da noção conceitual e prática das relações intergovernamentais como um novo par de lentes (WRIGHT, 1997), como ferramenta, no exercício de compreender e estabelecer os papéis dos entes federados nas políticas educacionais.

Em sua explicitação conceitual, as RIG's são compreendidas por Wright (1997, p. 68, grifo e tradução nossa) como "[...] um importante corpo de atividades ou de interaçoes que ocorrem entre as unidades governamentais de todos os tipos dentro do sistema federal' '. Para esse autor, o sentido da noção de relações intergovernamentais pode ser entendido como ação na qual se evidenciam aspectos básicos, como a ação de variados sujeitos, diversos agentes da administração e gestão, os cidadãos como um todo, as entidades governamentais de todos os tipos, tamanhos e orientações e a presença dessa ação em toda parte em nossos sistemas políticos, fermentando todo o plano governamental.

Tendo por base essas noções, acredita-se, igualmente a Sano (2008), que o entendimento das RIG's sugere compreender os movimentos relacionais entres as unidades governamentais, a atuação dos agentes e os processos de financiamento, tidos como fatores de análise fundamentais nesse tema. Nesse sentido, é importante refletir as unidades governamentais como faces institucionais diversificadas, os agentes como representação do poder interventor do elemento humano e o financiamento como condição para a concretização eficiente da atuação das unidades governamentais em determinada política. No que se refere à tarefa municipal na formulação e execução de políticas educacionais, tais fatores situam-se como peças da imbricada interpenetração e regulação entre União, estados e municípios, advindas da prática federalista. É possível perceber que a dinâmica das RIG's

\footnotetext{
${ }^{1}$ Essa definição é adotada por Deil S. Wright com base no conceito cunhado por Willian Anderson na obra Intergovernamental Relations in Review (1960), a quem o autor atribui o mérito de haver contribuído, substancialmente, para a elaboração desse conceito na década de 1930 nos Estados Unidos.
} 
se manifesta em práticas em que o jogo federativo pode produzir relações de cooperação, de competição ou de equilíbrio entre cooperação/competição por meio de uma coordenação federativa (ABRUCIO; COSTA, 1998), considerando a concentração e a difusão de poder entre os entes.

Nesse sentido, analisando as diversas abordagens do federalismo, Franzese (2010) evidencia a preferência pela noção de "federalismo como um pacto", originário desse acordo de confiança estabelecido entre os entes federativos com base no mútuo reconhecimento, tolerância e respeito entre as partes. Nesse modelo teórico, a produção de arranjos institucionais não é baseada em um só centro, mas enseja uma estrutura com múltiplos centros de poder, onde se combinam disposições constitucionais, normas infraconstitucionais e relações intergovernamentais de forma dinâmica. Na compreensão da autora, essa teoria serve de fundamento para exames cuja atenção esteja focada na interação de unidades federativas, ou seja, nas relações intergovernamentais.

A utilização do conceito de federalismo como pacto justifica-se na medida em que se busca compreender os arranjos que esse formato de organização tem no Brasil, considerando, sobretudo, seu teor cooperativo, que incide no estabelecimento de relações entre os entes federados igualmente colaborativas (FRANZESE, 2010). Isso exige a compreensão dos traços que a adoção desse regime na experiência brasileira traz para as conexões dos entes como diversificados centros de poder na formulação e execução de políticas educacionais, para as decorrentes estratégias de centralização/descentralização para esse fim, e, consequentemente, para a atuação autônoma municipal quanto à elaboração e à oferta de políticas de educação.

O desafio das relações intergovernamentais está, então, fixado em problemas relacionados aos centros de poder que se constituiriam no arranjo federativo brasileiro, e neles, a atuação de agentes diversos e de vários interesses em negociação, em distintos espaços governamentais. Por tais considerações, compreender as relações intergovernamentais no espaço brasileiro é extremamente necessário, sobretudo, porque a tensão entre centralização e descentralização, as formas de colaboração ou relacionamento entre a União e os entes federados são questões fundamentais para a compreensão da Política Educacional no Brasil.

A discussão das RIG's, no escopo deste trabalho assenta-se, em especial, sob a transição histórica com origem na redemocratização brasileira durante os anos 1980, em especial, porque, desde a abertura democrática, o padrão de RIG’s vem se metamorfoseando. A própria redemocratização é apresentada por Sano (2008) como uma mudança no padrão das RIG’s e uma conjuntura crítica, em que a conjunção de situações diversas, como, por exemplo, a crise fiscal, a eleição de governadores (1982), a promulgação da Constituição de 1988 e a descentralização das políticas constituem fatores de mudanças. 
A experiência do estabelecimento de relações intergovernamentais no Brasil, desde a fase de redemocratização, está, então, para o modelo de federalismo dos dispositivos constitucionais de 1988, reconhecido como cooperativo (CURY, 2006, 2010; ARAÚJO, 2010a). Esse federalismo é, também, um “federalismo tridimensional" (ARAÚJO, 2010a), assim chamado por ser um sistema de três níveis (triplo federalismo) em face da incorporação dos municípios, junto aos estados, como integrantes da Federação. Tal incorporação exige da Federação colocar no centro da agenda a constituição de mecanismos de coordenação/cooperação que incluam milhares de municípios bastante heterogêneos, tanto do ponto de vista econômico-tributário como político e social (COSTA, 2010).

No Brasil, essa característica tridimensional com diversas possibilidades de eixos de ação na elaboração das relações intergovernamentais, e com a opção normativa pelo federalismo cooperativo, aumenta a complexidade da aferição dos papéis das unidades federativas. $\mathrm{O}$ desenho das relações se expressa ainda mais difícil quando um desses eixos se evidencia, perdendo a natureza tridimensional/ cooperativa que o modelo sugere. No Brasil, ao sabor da estrutura descentralizadora das políticas, ora se acentuam relações mais intensas entre União e municípios, ora entre Estado e municípios, e assim por diante, em detrimento da ação conjunta, coordenada e articulada para um esforço de assunção das competências que the são conferidas pelo dispositivo legal ${ }^{2}$.

Ancorado no pensamento de Araújo (2010b) acerca da distribuição das competências federativas, pode-se aferir a ideia de que, quando se trata de "competência", fala-se da 'capacidade de a autoridade possuir atribuições', do 'poder que se confere a determinado ente federado para exercer suas funções’. O papel exercido, noção fundamental neste estudo, está numa outra dimensão, marcado que é pelas especificidades de um território, pelas regulações do espaço da gestão e pela capacidade do ente federado em atuar ante as características formais e o funcionamento dos sistemas políticos no seu entorno. Desse modo, o papel exercido se aproxima bem mais de prática efetiva no exercício das funções atribuídas, geralmente afetadas por processos decisórios particulares e localizados e pelas regulações locais. No escopo deste exame, a promoção das políticas de formação continuada de alfabetizadores, nos municípios, é mais um papel atribuído do que exercido.

As relações intergovernamentais no Brasil não podem prescindir do esclarecimento teórico e prático das noções de coordenação federativa e de colaboração, tomadas muitas vezes como sinônimas nas ações do Governo Federal e dos

\footnotetext{
${ }^{2}$ A distribuição das competências exclusivas e privativas da União e das competências comuns e concorrentes entre os entes federados pode ser bem visualizada nos art. 21 a 23 da Constituição Federativa de 1988. No âmbito da educação a Lei de Diretrizes e Bases, Lei no 9.394/1996, estabelece em seus art. $8^{\circ}$ ao Art. 11, as funções dos entes federados.
} 
governos subnacionais. O esclarecimento feito por Araújo (2010b) nesse sentido, ajuda a separar as duas questões. Para a autora, a ideia de coordenação federativa é um procedimento que busca resultado comum com origem no Governo Central, não obstante a autonomia dos entes federados. Já a colaboração federativa pode ser entendida como o modo de atribuições e exercício das competências concorrentes e comuns, em que a tomada de decisões e o exercício das competências são conjuntos e não isolados.

Para Abrucio (2005), a coordenação federativa é considerada como um vetor analítico pouco utilizado no âmbito do federalismo brasileiro. Ainda segundo o autor, tratar da questão da coordenação intergovernamental, ou seja, das formas de integração, compartilhamento e decisão conjunta entre as unidades que compõem o pacto federativo, surge como temática necessária diante das complexificações ocorridas nas RIG's nos últimos tempos por força da convivência de tendências conflituosas atuais, sobretudo pela ausência dos mecanismos que regem essa coordenação. A coordenação federativa das interações dos entes federados evidencia-se, como já visto, pela necessidade do compartilhamento em arenas decisórias dos processos de formulação e execução de políticas. Ela aparece, dessa forma, como tarefa mais ampla, que ultrapassa a ideia de responsabilidade do Governo Federal e se firma numa nova compreensão, na criação de mecanismos de coordenação intergovernamental, ou de arenas intergovernamentais de debate e deliberação, conforme adotado por Abrucio (2010). A coordenação mais clara e efetiva da União não somente é possível como desejável, como cita Cury (2010), mas sugere maior definição dos moldes em que ela ocorrerá, vendo-a como reguladora da assunção dos papéis de cada ente federado.

Ainda em relação à possibilidade de coordenação federativa, a posição de Arretche (2004) é de que tal capacidade está diretamente afetada pelo modo como estão estruturadas as relações federativas em políticas particulares. Nesse entendimento, distintas políticas sociais determinam variadas relações e níveis de autoridades, ao lado de desigual distribuição de funções quanto à formulação e execução dessas políticas, bem como na sua coordenação entre os níveis. Para a autora, o formato da gestão concentrada no Governo Federal produz muitas vantagens para as RIG's e para o sucesso das políticas, porque possibilita maior coordenação dos objetivos previstos, evitando conflitos e custo mais elevado na implementação por força da ação dos vários níveis de governo; além disso, a concentração do financiamento promove melhores resultados distributivos. A questão dos objetivos previstos, no entanto, aponta para a discussão do nível de colaboração no desenho desses objetivos, para que sejam perseguidos pelo conjunto no quadro de uma ação coordenada.

Nessa nova compreensão, o exercício da cooperação federativa é parte componente que não se limita, por exemplo, à cooperação na execução, na condução 
e gestão de determinada política, mas se expressa na tomada de decisão e no exercício das funções de forma conjunta, como defende Araújo (2010b). A colaboração desejada não se processa das margens do sistema para o centro, do subnacional para o nacional, dos municípios para a União (ou dos estados para a União), numa perspectiva hierarquizada, mas se materializa como ação conjunta e articulada na assunção dos papéis governamentais de cada unidade federativa com um objetivo comum. Indica associação dos entes federados, participação e contribuição de cada um, entendimento e regulação entre os envolvidos (FREITAS, 2012). É nestes termos que se defende a constituição das relações federativas claras, seja no exercício das competências comuns, seja nas concorrentes.

Franzese (2010), considerando a matriz do "federalismo como pacto", antes referida, evidencia a possibilidade de compreensão do adjetivo cooperativo como portador de uma relação não muito tranquila e amigável entre as esferas de governo, ao contrário do que supõe o nome. Na prática desse modelo, 'cooperação', segundo a autora, pode-se relacionar à obrigatoriedade de que os governos trabalhem juntos, não por opção, mas por força dos dispositivos constitucionais e pela dinâmica do desenho federativo. Essa relação, que é pactuante mas mantém lutas internas, e se faz assim, ora antagônica, ora coercitiva, é própria do pacto, segundo Morresi (2006), que se mostra como ideia que parece se ocupar, de modo geral, da concordância, do acordo pacífico, mas que não implica a negação superadora do conflito. Com base no autor, pode-se dizer que a ocultação do conflito no pacto permite, por um lado, a legitimação da ação conjunta, colaborativa, por assim dizer, entre as partes pactuantes, e, por outro, evidencia, por vezes, um processo de renegação, em que o perdedor/pactuante internaliza a subordinação como se fosse decisão sua. Nesse sentido, afirma-se neste estudo, que a presença do modelo cooperativo, na execução das políticas induzidas pode ser tida como veículo de subordinação de um ente ao outro por meio do pacto federativo e de suas nuanças colaborativas.

Acredita-se, igualmente a Abrucio (2001), que a cooperação não significa a imposição unilateral de ações conjuntas, evidenciando mais subordinação do que parceria entre os entes federados. O pacto cooperativo, desse modo, não pode ser compreendido e efetivado como instrumento para escamotear o conflito, mantendo relações de domínio de um pactuante sobre o outro e determinando ganhadores e perdedores; tampouco gerando cooperações forçosas de uma unidade federativa com a outra. No âmbito da política e gestão da educação, encontrar mecanismos para definir o papel de cada um no contexto da efetivação de objetivos comuns parece ser o melhor caminho para o desafio da cooperação.

Quanto à organização de mecanismos cooperativos, entende-se que eles compreendem três dispositivos importantes - intervenção, negociação e compartilhamento. Intervenção no sentido da atuação mais apropriada da coordenação 
da União nas várias atuações subnacionais, das relações entre a União e estes, bem como entre estados e municípios; negociação com vistas a estabelecer espaços e condições para os consensos entre interesses e para os acordos entre os entes federados em relação às responsabilidades com determinadas política em suas esferas específicas; e compartilhamento naquilo que se refere à necessidade democrática da participação dos sujeitos e das instituições envolvidas nos processos decisórios de elaboração dos objetivos e de execução das políticas. Colaboração, nesse formato, passa a incorporar outros sentidos, transpondo a execução, assume a forma de práticas de participação na criação, de interposição decisória nos destinos das políticas e nas suas formas de materialização e de tomada de posição concreta na sua execução nas unidades governamentais.

É neste sentido do desvelamento da ideia de coordenação intergovernamental e da operacionalização da colaboração, que existe a crença da necessidade de estabelecer, como postula Araújo (2010a), a justa distribuição de poder, autoridade e recursos entre os entes federados, com independência e interpenetração dos níveis de governos em suas relações e sem prejuízo para o projeto de desenvolvimento nacional, no qual um dos elementos é a educação.

\section{Relações estado/municípios nas políticas de formação continuada de alfabetizadores no Ceará: colaboração e papel exercido}

Essa seção se propõe a colocar algumas bases contextuais para se compreender como se firmam as relações federativas e o papel municipal nas políticas de alfabetização em âmbito local, nas práticas de formação dos professores alfabetizadores, e as formas de colaboração entre Estado e municípios cearenses nesse campo de atuação.

No Plano de Governo Cearense de 2003 a 2006, no recorte deste estudo, o planejamento e a avaliação anual estão associados a eixos de trabalho listados no documento-matriz do Plano de Governo à época. Entre os chamados Eixos de Articulação do Plano está especificado o eixo "Ceará Vida Melhor", que se apresenta como destinado à melhoria das condições de vida da população cearense, sobressaindo aquelas referentes à educação. As linhas de ações do eixo acentuam o reconhecimento da educação para o pleno desenvolvimento do ser humano, no qual o investimento do Estado em um ensino de qualidade emerge como primordial, em especial na educação permanente e aprendizado contínuo, garantindo, por esse meio, o domínio das habilidades de leitura, interpretação e escrita. Para a consecução desse objetivo, o documento traz o modelo operacional:

As políticas serão concebidas e implementadas de forma planejada, integrada, descentralizada e participativa nas três esferas governamentais, iniciativas privadas, entidades representativas da comunidade e organizações não- 
governamentais, buscando sempre a ação em parceria e a promoção da auto-gestão municipal. (CEARÁ, 2003b, p. 101, grifo nosso).

Segundo Bezerra (2010), isso se explica porque o Plano de Governo do Ceará assenta-se no arcabouço gestionário e no marco legal adequados à passagem definitiva da gestão dos serviços públicos para a esfera pública não estatal, mantendo a forte tendência descentralizadora das administrações anteriores (1995-2002), sob o argumento de que os resultados acontecem nos municípios e nas comunidades, onde o raio de ação do Estado é limitado. Essa herança se explica porque, segundo Ramos, Lira e Soares (2012), a centralidade da política dos governos que antecederam a gestão 2003-2006 é o fortalecimento da capacidade gerencial dos níveis central, regional, municipal e escolar para oferecerem, com eficiência, os serviços.

No campo da educação, destaca-se, como peça fundamental do governo cearense a implementação do Plano de Educação Básica 2003-2006 (CEARÁ, 2004a) que, alinhado ao documento matriz, vem expressando as intenções do Estado na educação. De acordo com o Plano, a partir de amplos processos de participação dos educadores e da sociedade até 2003, se delinearam dez desafios para o desenvolvimento da educação cearense a partir daquele ano, destacando-se aqui referências ao desafio 07, "[...] Aprimoramento do processo de formação e valorização dos servidores da educação”; e o desafio 10, “[...] Regulamentação e efetivação do regime de colaboração Estado/Municípios. (CEARÁ, 2004a, p. 17, grifo nosso). Esses temas balizam a aferição das práticas referentes às relações intergovernamentais, e nelas as ações de descentralização e de municipalização das políticas de formação continuada de alfabetizadores e o papel exercido pelo estado e pelos municípios cearenses no período.

Considerando o panorama cearense da época, a análise das incorporações das políticas de formação continuada de alfabetizadores formuladas no âmbito federal e estadual e sua relação com as ações desenvolvidas nas municipalidades cearenses, se mostram como aspectos que denotam suas especificidades. Essa especificidade cearense pode ser sentida no exame feito em Rabelo (2010) acerca da implementação do Programa de Formação de Alfabetizadores (Profa) no Ceará, como análise que situa o modo distinto que o Estado e os municípios cearenses incorporaram, cada um ao seu modo, essa política advinda do eixo federal. De modo geral, pode-se dizer, com base no autor, que a finalização desse programa no Ceará, em 2002 - quando em âmbito federal se finaliza a gestão do presidente Fernando Henrique Cardoso - põe em xeque se houve alguma iniciativa para a continuidade das políticas na área, ficando esse espaço em aberto na transição dos governos de 2002 a 2003 no Estado do Ceará e anos seguintes. Assim, pode-se atestar que neste contexto se evidencia um "hiato" na política de formação continuada de alfabetizadores no Ceará, extensivo ao quadro nacional. 
Com base em dados coletados e analisados em Rabelo (2010), a experiência de finalização do Profa em municípios cearenses desde 2002, não implanta a cultura de formação continuada requerida nos objetivos do programa (BRASIL, 2001), apesar de deixar rastros de continuidade de alguns instrumentos, como cadernos de estudo, manuais e vídeos, usados em práticas de formação de modo isolado e autônomo em alguns municípios, com ou sem o suporte da Secretaria Estadual da Educação Básica. Provavelmente, por essa razão se explique o fato de ainda constar em alguns registros no Relatório de Gestão da Educação do período de 2003 a 2006 (CEARÁ, 2006a) e nas Mensagens Governamentais (CEARÁ, 2003a, 2004b, 2005). O Programa é representativo de uma das práticas desenvolvidas no Ceará que se realizou até 2002, em termos de experiências e parcerias entre União, Estado e municípios na implementação de políticas de formação continuada de alfabetizadores em larga escala.

Efetivamente, conforme a Mensagem Governamental de 2003, o Profa, desenvolvido no Estado em 2001 e 2002, teria priorizado apenas os professores municipais que atuavam ou iriam atuar no Ciclo Básico de Alfabetização. Isso leva a crer que tenha se constituído, supostamente, a política de formação de alfabetizadores até o ano de 2002. Essa informação, no entanto, não assegura que tenha sido a única oportunidade oferecida aos municípios, ou que, à revelia da sentida ausência de políticas na área, não tenham se desenvolvido experiências de formulação e de execução de iniciativas dessa natureza.

Conforme anexo 2 do documento de trabalho intitulado "A Reforma da Educação Básica no Ceará: uma construção coletiva” (CEARÁ, 2001), alusivo ao projeto educacional desenvolvido por volta de 2001, o Ciclo Básico de Alfabetização fazia parte de uma espécie de pacto entre a Secretaria Estadual da Educação Básica e secretários municipais de educação, firmado em maio de 2001. Neste, os gestores estaduais e municipais assumiam uma série de compromissos para a composição da Agenda Educacional destinada à faixa etária de 6 a 8 anos, apontando os caminhos das políticas de alfabetização e de formação de alfabetizadores que pudessem ser formuladas daquele momento em diante. Entre outros aspectos, figuravam objetivos como:

[...] Atuar de forma cooperada na formação de educadores em exercício nas séries e ciclos iniciais do Ensino Fundamental, sobretudo em Programas de Alfabetização.

Promover a articulação dos três primeiros anos letivos do Ensino Fundamental visando a consolidação do processo de alfabetização.

Estruturar, de forma cooperada e democrática, serviço de acompanhamento pedagógico que promova o apoio aos docentes em exercício nas séries/ciclos iniciais do Ensino Fundamental [...]. (CEARÁ, 2001, p. 22, grifo nosso).

Independentemente das questões informadas nos documentos, essas referências assinalam e solidificam a compreensão de que existe um percurso, 
aprofundado em 2001, constituído nas bases da sociedade e das instituições educacionais cearenses, tanto de cunho governamental, quanto não governamental, apontando proposições para uma "Política Estadual de Alfabetização", que deveria ser formalizada na gestão seguinte (2003-2006).

De modo geral, nota-se, nas Mensagens Governamentais (CEARÁ, 2004b, 2005, 2006b), que o desafio do "aprimoramento do processo de formação e valorização dos servidores da educação", no tema específico da formação continuada dos professores e de alfabetizadores, aparece, apenas, na realização de ações, tais como: a continuidade e estruturação dos centros de formação de professores; oficina de leitura e escrita, envolvendo 1.130 professores que atuam nos projetos de implementação do Ciclo Básico de Alfabetização; a formação para os 80 coordenadores estaduais e municipais do Programa PCN's em Ação em 2004, programa que pode privilegiar a formação dos alfabetizadores nos módulos do PCN's de Alfabetização. No conjunto das ações em 2003, destacam-se também aquelas expressas no plano da alfabetização de jovens e adultos, citadas na Mensagem Governamental de 2004 (CEARÁ, 2004b, p. 20), como “[...] formação continuada para 8.017 alfabetizadores envolvidos no 'Projeto Escola do Novo Milênio', além de apoio técnico pedagógico ao Projeto Alfabetização Voluntária, com capacitação de 197 alfabetizadores".

No âmbito da constituição do desafio acerca da "implementação do Regime de Colaboração cearense”, constam no Relatório de Gestão 2003-2006 (CEARÁ, 2006a) ações estaduais distribuídas em projetos e programas específicos. No que se refere ao "Fundo Estadual de Combate à Pobreza" (Fecop), relata-se o desenvolvimento de atividades voltadas para a área de alfabetização que podem trazer elementos relativos a esforços de criação de oportunidades de formação de alfabetizadores. Tomando o texto sobre as ações do Fundo Estadual de Combate à Pobreza (Fecop) - Área: Educação Básica (CEARÁ, 2004c), fica revelada a ação focalizada que o programa apresenta para o problema da alfabetização das crianças na escola. Por meio do Fecop, a Secretaria Estadual da Educação Básica propôs-se desenvolver uma experiência iniciada em 2004 nos dez municípios de menor IDH-M do Ceará, implementando dois projetos, o "Prêmio Professor Alfabetizador" e o projeto "Bolsa Aluno Melhor", com o objetivo de atuar nas redes municipais de ensino. A ação política procurava "[...] reverter os indicadores de rendimento do Ensino Fundamental - reprovação e abandono - e o desempenho dos alunos nas duas séries iniciais, através do fortalecimento do processo de alfabetização". (CEARÁ, 2004c, p. 08).

O "Prêmio Professor Alfabetizador", iniciado em 2004, foi dirigido aos docentes que atuavam nas $1^{a} \mathrm{e} 2^{\mathrm{a}}$ séries das redes municipais e tinha como objetivo melhorar os indicadores educacionais, visando à elevação do patamar e qualidade de vida e das condições sociais e econômicas das populações em municípios com 
menores IDM (2002) e estimular os avanços no processo de alfabetização. Utilizou, como metodologia, a avaliação diagnóstica da leitura e escrita de crianças no final das $1^{\mathrm{a}}$ e $2^{\mathrm{a}}$ séries, com base em instrumento desenvolvido pela Secretaria Estadual de Educação. O resultado do diagnóstico, realizado em novembro de cada ano, premiava cinco professores de cada município que obtivessem melhores percentuais de alfabetização (CEARÁ, 2004c). O "Bolsa Aluno Melhor" atuava como mecanismo de transferência direta de renda para alunos do Ensino Médio $\left(1^{a}, 2^{a}\right.$ e $3^{a}$ séries) para que colaborassem como monitores junto às crianças e adolescentes do Ensino Fundamental da rede municipal, trabalhando com as disciplinas Língua Portuguesa e Matemática.

Evidencia-se que as ações desenvolvidas pela Secretaria Estadual de Educação Básica se caracterizam sempre na direção do problema da alfabetização, reconhecido há algum tempo, como um desafio da educação estadual, mas não se qualifica como iniciativa que atinja o problema de forma estrutural. São iniciativas de oferta estadual para a área municipal, priorizadas pelos critérios da gestão estadual, que reduz os municípios à função receptiva, operacionalizando as ideias formuladas e financiadas pela gestão estadual por meio do Fecop. A iniciativa reveste-se de teor subserviente na relação intergovernamental, de subordinação no pacto (MORRESI, 2006), evidenciando a força da dosagem de recursos em detrimento do esforço colaborativo.

Difere completamente da ação realizada, desde 2001, pela Secretaria Municipal de Educação de Sobral, município localizado no semiárido, noroeste do Estado do Ceará, a $230 \mathrm{Km}$ de Fortaleza. A experiência dessa municipalidade, visando à solidificação de uma política de educação com foco na aprendizagem e prioridade para a alfabetização nas séries iniciais, é apresentada no documento "Vencendo o desafio da aprendizagem nas séries inicias: a experiência de Sobral/ CE” (BRASIL, 2005b) do Instituto Nacional de Estudos e Pesquisas Educacionais Anísio Teixeira (Inep) e em pesquisas da Organização das Nações Unidas para a Educação, a Ciência e a Cultura (Unesco), a exemplo da obra "Políticas docentes no Brasil: um estado da arte" (GATTI; BARRETO; ANDRÉ, 2011). Os documentos sinalizam o valor da experiência desse município na formação continuada dos professores alfabetizadores, ao mesmo tempo que apontam para as forças internas que mobilizam mudanças nesse sentido, no espaço da autonomia municipal.

A experiência de Sobral suscita questões muito significativas para este estudo: 1) sinaliza essa atuação e tomada de posição com a necessidade de políticas de alfabetização no Ceará, suficientemente latente nos dados do Saeb $2001^{3}$ e,

\footnotetext{
${ }^{3}$ Dados do Saeb 2001 revelaram, à época, que quanto às competências a serem adquiridas por alunos da $4^{\mathrm{a}}$ série do Ensino Fundamental em Língua Portuguesa, grande parte dos estudantes cearenses se encontravam na escala de desempenho ruim, figurando com $37,73 \%$ em estádio muito crítico, $37,59 \%$ crítico, e $22,54 \%$ em estádio intermediário. Em outras palavras, a maioria dos alunos não conseguiu atingir um patamar que
} 
sobretudo, nas realidades específicas dos municípios; 2) revela a necessidade de articular sempre à política de alfabetização iniciativas de investimento e de formalização de programas de formação continuada dos alfabetizadores; 3) mesmo considerando a importância das relações colaborativas entre municípios e estados e com a sociedade civil, assim como o papel indutor do Governo Estadual do Ceará, no caso das políticas de alfabetização e de formação de alfabetizadores, o processo parece que se inverteu.

De modo geral, a experiência autônoma de um município serve de mote para a mobilização das instituições educacionais cearenses e demais organizações da sociedade civil para o problema em evidência no Ceará, como a realizada pelo "Comitê Cearense pela Eliminação do Analfabetismo Escolar" (CCEAE) a partir de 20044. A criação desse Comitê situa-se como marginal aos indicativos de políticas para essa área concretamente efetivadas pela gestão da educação cearense à época, mas se mostra como divisor de águas no que se pode chamar de constituição de propostas para a política cearense de alfabetização e de formação de alfabetizadores.

Mesmo assim, conforme os relatos dos documentos governamentais analisados, acerca da influência do debate iniciado pela Assembleia Legislativa por meio da experiência do "Comitê Cearense pela Eliminação do Analfabetismo Escolar" (CCEAE) e pelos resultados por ele evidenciados, a Secretaria Estadual da Educação Básica não expressa políticas universais compartilhadas com esse fim. Ao contrário, lança o "Projeto Lendo você fica sabendo", criado em 2006, que surge como uma das ações que procuravam promover o processo de alfabetização nas duas séries iniciais do Ensino Fundamental. Semelhante à maioria das ações formuladas e implementadas no período por essa Secretaria, centrada na atenção à alfabetização e visando colaborar com os municípios, o projeto foi implantado, apenas, em cinco deles - Catarina, Moraújo, Mombaça, Pires Ferreira e Massapê - restringindo-se, novamente, a práticas focalizadas (CEARÁ, 2006a).

Além do "Projeto Lendo Você fica Sabendo", também em 2006, por fim, desenvolve-se uma ação à qual o Estado atribui a natureza homogeneizada e em larga escala, o Pró-Letramento. Essa foi originada em âmbito federal e formalizada para ser implementada na relação colaborativa dos federados. No Ceará, o Programa se efetivou com a formação de 360 tutores que formariam 19.000 professores

demonstrasse estes como leitores com nível de compreensão de textos adequados para a $4^{\text {a }}$ série.

${ }^{4}$ Essa realidade se mostra clara, uma vez que a ação do Comitê Cearense pela Eliminação do Analfabetismo Escolar (CCEAE), vista como propulsora para a "descoberta" no âmbito cearense do apelo por políticas sólidas na área de alfabetização de crianças nas primeiras séries do Ensino Fundamental por volta de 2004, teve origem motivada pelo sucesso conseguido pelo Município de Sobral. O trabalho do Comitê Cearense teve como presidente o deputado Ivo Ferreira Gomes, irmão do atual governador cearense, Cid Gomes, prefeito de Sobral quando da criação e implementação da experiência naquele Município. 
em 138 municípios com adesão ao programa (CEARÁ, 2006b). Conforme a Mensagem Governamental de 2006 (CEARÁ, 2006b), o Pró-letramento tem as primeiras atividades realizadas em 2005, por meio da formação dos responsáveis estaduais e locais para a implementação da política em 2006.

O Pró-Letramento foi implantado, no Ceará, em decorrência de sua integração ao quadro de estados prioritários, ao lado de outros três estados nordestinos (Bahia, Rio Grande do Norte e Maranhão), segundo os Relatórios da Gestão do MEC (BRASIL, 2006a, 2006b). Os dados referentes à implementação do Pró-Letramento no Ceará em 2006, nessa fase de execução em Estados prioritários, não são visualizados na Mensagem Governamental cearense de 2007, correspondentes às ações do último ano no governo de 2003-2006. No Pró-Letramento, apesar do discurso de implementação em nome do perfil federativo e do regime de colaboração (BRASIL, 2007b), as relações se expressam no Ceará nos moldes verticais, e a colaboração se reduz a aderir e executar o Programa com suporte das universidades e materiais produzidos no MEC, por meio da Rede Nacional de Formação Continuada (REDE), implementada, à época, pelo governo federal. ${ }^{5}$

Essa visão sumariamente descrita das ações que podem evidenciar possíveis incorporações dos programas federais e estaduais no âmbito municipal para a formação de alfabetizadores, traz, à tona, algumas indicações de análise: a primeira questiona a extensão e a continuidade do Profa, pelo menos, até 2005, como Programa de Formação de Alfabetizadores em execução pela Secretaria Estadual da Educação à revelia de sua extinção desde 2002; a segunda, a notória ausência de registros sobre a Rede de Formação Continuada de Professores da Educação Básica (REDE), de cunho federal e os programas oferecidos por este meio que, de acordo com os relatórios da gestão do MEC (BRASIL, 2006a), teria sido ofertado a Estados e Municípios; a terceira, a efetiva adesão ao Pró-Letramento, expressa no documento estadual, já referido, e no relatório nacional. A quarta, de modo particular, traz as situações da não manifestação de sinais sobre o Praler, outro Programa federal amplo do período de 2003 a 2006 (BRASIL, 2007a) que não se anuncia nos dados aferidos no Ceará, e a efetivação de programas estaduais contingentes.

Com essas informações, evidenciam-se os limites da discussão às expressões de programas federais de formação continuada de alfabetizadores em municípios cearenses, que fica reservada à forma do Profa, e do Pró-Letramento e às

\footnotetext{
${ }^{5}$ A REDE é descrita nos documentos "Orientações Gerais - Rede Nacional de Formação Continuada de Professores da Educação Básica” (BRASIL, 2005a), que personifica bem a ação federal na formação continuada no período, e que se explicam na listagem de programas de formação para serem ofertados e negociados com os municípios. Dentro do grupo de universidades que integravam a Rede Nacional de Formação Continuada (REDE), a Universidade Federal de Minas Gerais (UFMG) ficou responsável pelo desenvolvimento do Programa no Ceará na área de Linguagem, por meio do CEALE (Centro de Alfabetização, Leitura e Escrita), órgão complementar da Faculdade de Educação da UFMG, criado em 1990 e integrante da REDE.
} 
iniciativas internas em estudo, como os projetos relacionados ao Ciclo Básico de Alfabetização, ao "Projeto Lendo Você Fica Sabendo" e às ações aliadas ao Fecop, que se sobressaem como sinais da ação da Seduc-CE na direção dos municípios para a formação de alfabetizadores. Por essa razão, é pertinente o seguinte questionamento: Que políticas foram incorporadas e executadas no plano municipal?

\section{O papel exercido: as políticas de formação continuada de alfabetizadores nos municípios de Jaguaruana e Palhano}

A análise sobre a função que deve ser atribuída, jurídica e administrativamente aos Municípios pesquisados - Jaguaruana e Palhano - nas políticas de formação continuada de alfabetizadores, se justifica pela busca de compreender o "papel exercido" por estes municípios nesse campo, considerando suas particularidades.

Pela discussão das políticas oriundas do eixo federal, conforme visto no conjunto dos dados recolhidos nos municípios, sobretudo nas entrevistas, pode-se asseverar que a continuidade do Profa no Ceará pela Secretaria Estadual, largamente comentada nas mensagens governamentais, é, na verdade, a decisão da continuidade autônoma do Profa pelos municípios, de modo opcional e com recursos próprios, realizada desde 2003. É consenso nessas possibilidades que o material fornecido pelo MEC por via do programa foi o que perdurou e foi reutilizado pelos agentes municipais na sua operacionalização. No caso dos municípios em questão, esse processo toma rumos próprios em cada município.

Os dados recolhidos nas entrevistas com os gestores acusam a continuidade do Profa no Município de Palhano, não exatamente reformulado como um programa municipal, mas recorrendo aos aportes deixados pelo programa.

[...] Foi o próprio município que resolveu, por iniciativa dar continuidade. Então foi dada assistência na questão de cópia, de apostila para os professores, o local, deslocamento dos professores até o local. Foram ações implementadas pelo próprio município pra dar continuidade. A gente tinha como objetivo oferecer o curso a todos os professores alfabetizadores, que no caso, seriam até o $4^{\circ}$ ano, que a gente considerava que era professor alfabetizador. (G4MUL) ${ }^{6}$.

Através da CREDE, a gente conseguiu o material, e a gente reproduziu para os professores. Eu como funcionária, como coordenadora fazia o curso, dava o curso voluntariamente, e o espaço era a biblioteca municipal. [...] O material era reproduzido através da Secretaria, eles tiravam as cópias para os professores. [...] O deslocamento também. (G5MUL).

\footnotetext{
${ }^{6}$ Trabalhou-se na pesquisa com secretários municipais de educação e técnicos integrantes da equipe, num total de 06 sujeitos, e optou-se por padronizar os códigos com as referências G1MUL, G2MUL, (...) G4MUL, etc., em alusão ao fato de que a gestão municipal é feita pela equipe, e não somente pelo representante legal da pasta.
} 
A Secretaria Municipal da Educação de Palhano, dessa forma, teria posteriormente incorporado o Profa e seus materiais para fortalecer a iniciativa municipal de preocupação com a formação continuada de alfabetizadores. É essa a proposição que surge dos relatos sequentes. A expansão da formação continuada apropriada a alfabetizadores a todo o primeiro segmento do Ensino Fundamental e gestores escolares, denota, neste estudo, o reconhecimento da necessidade de aproveitamento para contemplar as deficiências nas competências alfabetizadoras e dos problemas de alfabetização no âmbito municipal.

Também no Município de Jaguaruana, há referências à sua continuidade com as mesmas condições de Palhano. De fato, é relatado que, encerrado o prazo do MEC, tal município teria assumido a tarefa da continuidade como visto:

[...] de início estava aberto só para professores alfabetizadores. Nós conseguimos fazer com todos os professores até o quarto ano. Não terminamos no período que o MEC exigia. O município continuou com seus próprios recursos, reproduzindo material. Porque a primeira turma o material veio todo do MEC, mas da segunda turma em diante o material foi todo confeccionado pela secretaria de educação. (G3MUL).

A prática de continuidade, que pode se caracterizar como incorporação da responsabilidade municipal pela formação continuada dos professores alfabetizadores, acentua, de forma bem mais clara, que havia uma necessidade municipal em curso naquele momento, mesmo ocorrendo de forma deslocada do processo iniciado pelo programa federal finalizado em 2002. Nesse esforço de retornar àquele instrumento de formação, emergem também as ideias de voluntarismo e uso dos recursos locais para a continuidade do programa, como objetos que se incluem para que o Município pudesse manter essa oportunidade e conceder atenção ao conjunto dos docentes considerado alfabetizadores. Nota-se, neste sentido, que a atenção municipal às políticas de formação continuada de alfabetizadores se mostra como papel requerido, mediante a realidade de analfabetismo escolar. De fato, como afirmado há instantes, quando os municípios decidem continuar a formação, revela-se a demanda latente por qualificação desses alfabetizadores e a extensão do problema.

Pelo exposto, além da tarefa executora em grande parte com parcos suportes federais e estaduais, a solidificação dos programas não se estende como tarefa dos entes federados de modo colaborativo. A continuidade é requerida como papel essencialmente municipal, e com base em suas condições financeiras. No caso cearense, a esfera estadual serviu como estimuladora dessa tarefa isolada realizada pelo plano municipal, mas, discretamente, permaneceu como mediadora do processo de continuidade. É oportuno reafirmar, no entanto, de acordo com os dados, a importância da atuação do ente estadual nos movimentos de oferta e 
implementação das políticas formuladas no eixo federal. No plano do federalismo tripartite brasileiro (CURY, 2010), a exclusão de uma dessas unidades impacta na execução e no êxito da política, sobretudo no caso cearense, que já traz muito presente essa prática.

A continuidade do Profa do nas realidades educacionais no País, em especial no âmbito municipal, a saber, a urgência de iniciativas governamentais para a qualificação dos professores que atuavam nas salas de alfabetização, essencialmente municipais.

Saindo do campo de atuação do Profa, e entrando no âmbito da REDE, as oportunidades de formação de alfabetizadores implantadas pelos municípios se esvaem na total falta de reconhecimento do programa pelos municípios pesquisados. Dessa forma, há um salto que situa o recorte temporal de 2003 a 2006, marcado por um vácuo na elaboração de políticas nessa área que tenham chegado aos dois municípios pesquisados. Essa situação, possivelmente, é igual em todos os municípios da $10^{a}$ CREDE e no Ceará. Os produtos da REDE listados nos Catálogos (BRASIL, 2005a) não foram objeto de apreciação e de cruzamento com as demandas municipais do proposto programa de formação municipal.

Com relação ao Praler, com poucas diferenças, permanece também o elemento do desconhecimento sobre sua existência. O Praler não aparece, pois, a exemplo da REDE, como programa ofertado pelo nível federal, ou se aparece, se mostra nas falas dos gestores como duvidosa, numa lembrança enredada, ensejando confusões com outros possíveis programas de formação, não relacionados à formação dos alfabetizadores. Os relatos descritos por gestores dos dois municípios acentuam o pouco reconhecimento do programa na contextura municipal.

O Praler não chegou a ser aderido aqui no município. Que eu lembre não. Como agente vivia na época do PRO [...], eu posso não estar efetivamente lembrado dele, da implantação. Mas tenho quase certeza que o município não teve acesso, ou não teve implementação do Praler no Município. (G2MUL). Com relação a esse programa não tomamos conhecimento. Eu acredito que tenha sido também a questão de ter passado do período de adesão. Quando a secretaria tomou conhecimento, já havia encerrado as inscrições. Por não ter aderido, não houve na verdade a implementação do programa. (G4MUL).

Em ambos os municípios, o desconhecimento e a falta de identificação real do que seja o propósito do programa levam a crer que essa ação advinda do nível federal não assumiu expressões de implementação em larga escala nos municípios, já que, segundo o relatório do MEC, teria atingido no Ceará por volta de 379 escolas e 3.791 salas de aula, numa média de 10 salas por escola, não explicitando o que isso significa em municípios e alfabetizadores envolvidos. Nesse sentido, o Praler aparece como um programa no qual as relações intergovernamentais 
são estabelecidas do Governo Central para o local, com a exclusão do nível intermediário, o Estado. No Ceará, a presença estadual constituiu elemento que determina a entrada saudável dos programas nos municípios e a possibilidade de sua efetivação. A importância da presença e a atuação da esfera estadual na implementação de Programas são vistas pelos gestores de Jaguaruna e Palhano como no texto abaixo:

Todos os programas vinculados à Crede eram bom pra gente porque eles tinham uma cobrança, e a gente não perdia os prazos, não perdia os programas. Sempre quando vinham a nível federal, vinham mais soltos, adesão ou não do município, optativo ao município, às vezes, facultativo ao município. E quando vinham pelas instâncias estaduais elas vinham quase com os critérios de obrigatoriedade. (G2MUL).

Eu considero a gestão da [secretaria estadual] de grande relevância, e que ela dava assim muita assistência. Ela realmente queria, tinha sede de implementar uma educação de qualidade, voltada para todos os municípios. E o que eu achei interessante é que ela procurava sempre contemplar todos os municípios. Ela dava essa atenção. (G4MUL).

Essa presença da instância intermediária do Estado, por meio da Secretaria da Educação e de seus órgãos regionais, desse modo, se traduz ora em controle, ora em contribuição. Mantém a vigilância municipal em dar respostas aos influxos da indução federal e estadual e, ao mesmo tempo, enseja "obrigatoriedades", cria mecanismos de submissão e adesão "voluntária" municipal aos programas induzidos. Essa relação de proximidade firmada entre Estado e municípios na educação por meio desses órgãos se qualifica como a mais relacionada ao esforço de arenas coletivas na implementação de políticas (ABRUCIO, 2005). Como antes afirmado, oscilam, no entanto, entre práticas colaborativas e oferta mediada da indução de programas e políticas federais, e, sobretudo, estaduais.

Tratando-se do Projeto "Lendo Você Fica sabendo", as reações municipais à sua implementação e à tarefa da gestão local nesse projeto, manifestam-se nos dados também muito limitados, por sua natureza focalizada e por sua identificação com outros programas similares. Esse programa da Secretaria Estadual, que privilegiou ações de estímulo à leitura e à escrita para crianças e professores por meio de insumos na forma de kits de leitura em 04 municípios (CEARÁ, 2006a), não se enquadra como formação continuada de professores alfabetizadores municipais. O que mais se manifesta acerca de alguma atividade relacionada ao estímulo à leitura e à escrita é o município de Jaguaruana:

[...] Nós fizemos um trabalho em cima disso, agora eu não estou lembrado como foi que aderimos. Eu não estou muito lembrado não. Mas nós fizemos um trabalho. A gente ganhou material, literatura infantil, [...] e a gente fez, até 
numa semana pedagógica no município. A gente trabalhou, o tema foi baseado nisso aí, o tema da semana. (G1MUL).

O Lendo você fica sabendo [...] eu acho que foram poucos municípios que aderiram, por causa da questão que o recurso era próprio do município. A SEDUC dava um kit inicial. Só que aquele kit era básico, e você tinha que renovar semanalmente os livros, mudar. (G3MUL).

No Município de Palhano, ao contrário, apenas um gestor se manifestou sobre o assunto, denotando a ausência do projeto. Pelo exposto, é correto levar a efeito o fato de que houve uma ação de suporte com livros de literatura infantil e outros instrumentos na área para o estímulo de alunos e professores na leitura e na escrita. Apesar da necessidade de instrumentos que privilegiem a melhoria da ação do docente alfabetizador, a atitude estadual concede centralidade aos insumos, como livros de textos e os materiais pedagógicos, sem descer ao cerne das dificuldades municipais para os processos de alfabetização, expresso, sobretudo, na restrita qualidade da formação dos professores alfabetizadores e de seu efetivo trabalho em sala de aula, como atestado pelo CCEAE no âmbito do Estado do Ceará.

Os discursos mostram, enfim, que as ações federais e estaduais, no período de 2003 a 2006 trazem os sentimentos saudosos do Profa como programa voltado para a formação continuada dos alfabetizadores e que teve expressão significativa na realidade municipal, concomitante à chegada complementar e providencial do Pró-Letramento. Daí se falar de um espaço de ausência no período de 2003-2006 acerca dessa política em (in) definição. É como uma ponte que falta estabelecer. Essa ponte, que se mostra inexistente entre o Profa e o Pró-Letramento, como políticas de formação de alfabetizadores nos municípios, esconde suas manifestações.

O Pró-Letramento, então, embora não claramente uma política de formação continuada de alfabetizadores, é o programa que adquire forma mais nítida no Ceará, no que se refere ao esforço de estabelecer relações entre as esferas nacionais de poder para sua execução. É no final de 2006 que ele é ofertado aos Municípios cearenses e, no caso dos dois pesquisados, ultrapassa a mudança de gestão estadual em processo de implementação e sua execução se solidifica mesmo ofuscado pelas ações iniciais do programa estadual PAIC.

No âmbito do Município de Palhano, o programa não chegou a ser executado, apesar de seu reconhecimento e adesão pela Secretaria Municipal. De acordo com a fala dos gestores, a não efetivação do programa está relacionada mais às dificuldades da comunicação e intercâmbio nessa relação hierarquizada com a oferta federal do que com a vontade municipal de implementá-lo.

Foi também através de adesão. Só que não houve implementação. Em virtude do Município não ter sido contemplado. A gente colocou o cadastramento 
dos professores. Inclusive, na época, eu tomei a frente deste cadastramento, e a gente enviou. Só que eu acho que nós perdemos o prazo. (G4MUL).

Foi feita a adesão, mas não chegou a acontecer não no município. Por qual motivo eu não sei te informar. [...] Acho que foi descuido do município, acho que a gente acabou se descuidando [...] Acho que se a gente tivesse tido mais atenção, tivesse ficado mais atento, exigido mais, talvez tivesse até conseguido esses cursos. (G5MUL).

A comum atuação de Palhano às ofertas estaduais e federais, na qual se portava com facilidade mediante os contratos de adesão, como visto em outros programas, aparece no caso do Pró-Letramento sem manifestação positiva. A negligência relatada pelos gestores diante de uma política de formação que beneficiaria os professores, expressa o deslize do papel municipal na estrutura organizacional do programa, que requeria sua atuação de maneira integrada e com as competências específicas. Quanto à autonomia crescente das formas da gestão e do regime de colaboração defendido no manual do programa (BRASIL, 2007b), a "desatenção" de Palhano não fica suficientemente explicada.

No Município de Jaguaruana, a relação com a implementação do Pró-Letramento parece encontrar espaços mais proveitosos, no sentido do reconhecimento do programa, das maiores articulações com o Município, da clareza na condução da política desde o nível federal. Os trechos sequentes sinalizam alguns elementos nesse sentido.

[...] o processo de adesão [foi] dentro da mesma sistemática, com a convocação das instâncias superiores e a adesão do município. Esse nós recebemos o comunicado, os ofícios, o termo de adesão [...]. Os convênios foram estabelecidos, as parcerias foram estabelecidas, e [a exigência] que os entes cumprissem rigorosamente aquilo que estava compactuado, e a gente aderiu [...]. (G2MUL).

O Pró-letramento foi o outro programa que chamo "carro-chefe" voltado para o português e para a matemática, porque ele trabalhava duas áreas especificas. E o município aderiu, nós tínhamos excelentes professores formadores, [...] E assim, o município aderiu e executou todas as ações do Pró-letramento. Nós tivemos, se eu não me engano, 8 turmas de Pró-letramento. (G3MUL).

Os elementos acentuados pelos gestores relativos à presença mais ativa e compartilhada apontam para uma atuação federal em que a presença da União no programa avança na relação com os municípios. Como numa ação desencadeadora, o Município, igualmente, assume com maior empenho e acompanhamento, a proposta federal. Tudo leva a crer que, quanto mais se clarifica a participação do Município nos movimentos de produção e distribuição da política, mais seu nível de compromisso e de responsabilidade no êxito do programa aumenta, porque se 
fortalece nesse modelo o Município e os demais entes, reforçando o pacto geral, repactuando-se sempre as relações intergovernamentais.

Com base na experiência de Jaguaruana, e considerando que há limites ainda na aferição desse programa em Palhano pela não implementação, parece correto dizer que a estrutura do Pró-Letramento e sua condução pautada na maior articulação dos sistemas, sob o mote da colaboração federativa anunciada nos seus manuais (BRASIL, 2007b), ensejam um movimento de maior comunicação, informação, e pactuações mais compartilhadas. A articulação entre os entes federados e a presença da coordenadora do MEC concede para a execução do Programa uma feição mais coordenada, mais conjunta, por assim dizer. Pelo recolhido nas entrevistas, o Pró-Letramento teve sua implementação nessa relação mais direta Município-MEC, o que situou a Secretaria Estadual Cearense e seus órgãos regionais em papéis mais limitados à divulgação. De fato, os manuais e guias do programa, mesmo atestando o contexto federativo, preveem a estrutura organizacional do programa assentada no Ministério da Educação (MEC), por meio da Secretaria de Educação Básica (SEB), nas universidades formadoras e nas redes públicas de ensino, por intermédio de adesão das secretarias municipais de educação (BRASIL, 2007b).

É possível asserir a essa altura a ideia de que a saudosa lembrança do Profa e a agradável aceitação do Pró-Letramento se insiram como o alívio municipal, eximindo-se, com efeito, de suas responsabilidades em ter instrumentos que possam oferecer aos alfabetizadores algumas oportunidades de melhoria em seu trabalho e, consequentemente, apontar melhorias nos resultados de alfabetização no âmbito municipal. Daí, a estranha correria municipal em aproveitar o que os programas federais estariam oferecendo como formação continuada de alfabetizadores, ainda que provisórios.

\section{Conclusão}

As iniciativas de uma política de colaboração entre os entes federados carecem de solidez, passando pelo desenvolvimento de ações mais consistentes e duradouras que deem suporte para que os municípios se apropriem dos programas induzidos. Dessa forma, o esforço de solidez e perseverança da União e do Estado para as políticas que requerem a participação municipal, sugerem a credibilidade dos programas pela via da durabilidade da proposta, da continuidade das ações e da prática colaborativa na formulação, e muito mais intensamente na implementação e execução. Solidez e continuidade somente se efetivam caso seja considerada a compatibilidade do programa ofertado com a natureza específica da gestão municipal, havendo diferenciações na prática de execução de um município para o outro. 
No caso em estudo, pode-se inferir que, embora se apresentem com posições, algumas vezes semelhantes em relação aos programas ofertados, às relações estabelecidas com a União e com o Estado e às formas de colaboração ou de rejeição do seu papel, os municípios pesquisados trazem posturas que os diferenciam. De fato, os relatos demonstram que essas especificidades não são somente geográficas, mas essencialmente históricas, políticas e administrativas em cada município. São os sujeitos locais, os gestores e técnicos, que atuam na configuração da execução das políticas externamente geradas. São as escolhas desses sujeitos ante a historicidade da política educacional municipal que conduzem a gestão de determinada política naquele determinado município.

De um lado, pode-se dizer que o Município de Jaguaruana se expressa mais arredio aos influxos federais e estaduais na incorporação e na implementação das políticas de formação, estabelecendo limites na sua operacionalização quanto às condições financeiras e técnicas. A preocupação com os recursos é um aspecto mais visível em Jaguaruana, é a restrição que mais se evidencia na implementação de políticas externas. Do ponto de vista da observação e análise dos relatos de pesquisa, fica explícito no pensamento dos gestores desse município o fato de que o cuidado tem mais relação com a vontade de reverter as condições do que de restringir as oportunidades municipais.

De outro lado, município de Palhano transparece ao sentir dessa pesquisa como mais aproximado das necessárias articulações com a União e o Estado. Nos aspectos da incorporação das ofertas federais e estadual, mostra-se com menores reações, revelando, na maioria dos casos, maior facilidade em aceitar o que é determinado e de pôr em execução os programas advindos, excetuando o caso do Pró-Letramento, analisado antes, no qual a adesão não foi operacionalizada por motivos técnicos. Tudo leva a crer que há maior proximidade com a gestão da Secretaria Estadual em muitos aspectos, viabilizando facilidades em dar encaminhamento a uma relação intergovernamental mais colaborativa, colocando a atuação municipal mais aberta para as ingerências estaduais e federais.

A competência para alfabetizar como demandada dos professores alfabetizadores é também situação presente nos dois municípios. Trata-se da dimensão local do apelo por políticas de alfabetização e de formação continuada de alfabetizadores tão bem observadas no âmbito federal e estadual. A consciência municipal da carência de alfabetizadores por formação específica não mobilizou agendas, tampouco iniciativas municipais ou articuladas para a situação ser amenizada. Para este estudo, essa atitude municipal precisa ser mais bem debatida. Defende-se a ideia de que, mediante a expressão do analfabetismo escolar e as dificuldades docentes em conduzir os processos de alfabetização, a iniciativa de uma ação mais convincente e qualificada não pode, somente, recair sobre a esfera municipal. 
Os ajustes municipais, para se adequar às políticas que lhe chegam, por sua vez, têm posicionamentos díspares. A gestão municipal, por sua autonomia e por suas especificidades, ora se ajustam ao programa, ora ajustam o programa. Nesse movimento, a efetividade e a feição que as políticas assumem no quadro municipal ficam à mercê do poder regulador municipal. Isso também se diferencia de município para município. No caso de Jaguaruana e Palhano como espaços da pesquisa, esse ajustamento da política ou da gestão municipal, e vice-versa, varia de acordo com a proposição e com a estrutura do programa. Em tese, em programas que atribuem maior presença federal e municipal nos processos de adesão, acompanhamento e continuidade do Programa, o equilíbrio se mostra mais presente.

No campo específico do estudo dessa investigação, que são os municípios cearenses pesquisados, de modo geral, pode-se falar em ausência de iniciativas internas, de tomada de posição, aqui chamadas de "silêncio" em relação às políticas de formação continuada de alfabetizadores no período de 2003 a 2006. Os municípios se manifestam reconhecendo que se limitam nesse campo a fazer o que vem do eixo federal, sem maiores acréscimos. Há também um "silêncio" nas políticas federais, e, sobretudo, no caso do Ceará na atuação da Secretaria da Educação, como gerente das ações educacionais de 2003 a 2006.

A ausência de tomada de posição, em nível federal, mas, acima de tudo, nos planos estadual e municipal, atesta, na perspectiva do federalismo educacional, a pouca capacidade dos entes federados em estabelecer reflexões conjuntas na busca de um pacto nacional nessa área. Essa ausência solicita a inserção nas agendas governamentais de uma política ampla e sólida de alfabetização e de formação continuada de alfabetizadores, operacionalizada de forma cooperativa entre os entes federados e, portanto, sob a coordenação federativa, como política pública requerida nas realidades municipais.

\section{Referências}

ABRUCIO, F. L. A reconstrução das funções governamentais no federalismo brasileiro. In: HOFMEISNTER, W.; CARNEIRO, J. M. B. Federalismo na Alemanha e no Brasil. São Paulo: Fundação Konrad Adenauer, Série Debates, v. 1, n. 22, abr. 2001. p. 95-105.

ABRUCIO, F. L. A coordenação federativa no Brasil: a experiência do período FHC e os desafios do governo Lula. Revista de Sociologia e Política, Curitiba, n. 24, p. 41-67, jun. 2005. DOI: 10.1590/S0104-44782005000100005

ABRUCIO, F. L. A dinâmica federativa da educação brasileira: diagnóstico e propostas de aperfeiçoamento. In: OLIVEIRA, R. P. de; SANTANA, W. Educação e federalismo no Brasil: combater as desigualdades, garantir a diversidade. Brasília: UNESCO, 2010. p. 39-70.

ABRUCIO, F. L.; COSTA, V. M. F. Reforma do Estado e o contexto federativo brasileiro. São Paulo: Fundação Konrad Adenauer, Centro de Estudos, Série Pesquisas, n. 12, 1998. 
ARAÚJO, G. C. Constituição, Federação e propostas para o novo plano nacional de educação: análise das propostas de organização nacional da educação brasileira a partir do Regime de Colaboração. Educação e Sociedade, Campinas, v. 31, n. 112, p. 749-768, jul./set., 2010a. DOI: 10.1590/S0101-73302010000300006

ARAÚJO, G. C. Direito à educação básica: a cooperação entre os entes federados. Revista Retratos da Escola, Brasília, v. 4, n. 7, p. 231-243, jul./dez., 2010 b.

ARRETCHE, M. Federalismo e políticas sociais no Brasil: problemas de coordenação e autonomia. Revista São Paulo em Perspectiva, São Paulo, v. 18, n. 2, p. 17-26, abr./jun. 2004. DOI: $10.1590 /$ S0102-88392004000200003

AZEVEDO, J. M. L. de. A colaboração da União e os mecanismos de gestão democrática da educação em municípios do Nordeste. In: GOUVEIA, A. B; PINTO, J. M. R; CORBUCCI, P. R. Federalismo e políticas educacionais na efetivação do direito à educação no Brasil. Brasília: IPEA, 2011. p. 173-197.

BEZERRA, J. E. B. Princípios da subsidiariedade, corporativismo e educação: para a crítica da gestão participativa. 2010. 384 f. Tese (Doutorado em Educação) - Universidade Federal do Ceará, Faculdade de Educação, Programa de Pós-Graduação em Educação Brasileira, Fortaleza, 2010.

BRASIL. Ministério da Educação- Secretaria da Educação Básica. Programa de Formação de Alfabetizadores: documento de apresentação. 2. ed. Brasília: 2001.

BRASIL. Ministério da Educação. Secretaria da Educação Básica. Orientações Gerais Objetivos, diretrizes, funcionamento. Rede Nacional de Formação Continuada de Professores da Educação Básica. Brasília, 2005a.

BRASIL. Instituto Nacional de Estudos e Pesquisas Educacionais Anísio Teixeira. Vencendo o desafio da aprendizagem nas séries iniciais: a experiência de Sobral/CE. Brasília: INEP, 2005b.

BRASIL. Ministério da Educação. Secretaria da Educação Básica. Relatório de gestão 2005/ Planejamento 2006. Brasília, jan. 2006a.

BRASIL. Ministério da Educação. Secretaria da Educação Básica. Relatório de gestão 2006. Brasília, dez. 2006b.

BRASIL. Ministério da Educação. Secretaria da Educação Básica. Programa de Apoio à Leitura e Escrita - PRALER - Guia Geral. Brasília, 2007a.

BRASIL. Ministério da Educação. Secretaria da Educação Básica. Pró-letramento: Programa de Formação Continuada de professores dos Anos/Séries Iniciais do Ensino Fundamental Guia Geral. Brasília, set. 2007b.

CEARÁ. Secretaria da Educação Básica. A reforma da Educação Básica no Ceará: uma construção coletiva. Documento de Trabalho. 2001. (Não publicado).

CEARÁ. Mensagem à Assembleia Legislativa: abertura da sessão legislativa. Fortaleza: SEPLAN, 2003a.

CEARÁ. Secretaria de Planejamento e Coordenação (SEPLAN). Ceará Cidadania: crescimento com inclusão social - Plano de Governo 2003-2006 - Administração Lúcio Alcântara. Fortaleza: SEPLAN, 2003b. 
CEARÁ. Secretaria da Educação Básica. Plano de Educação Básica Escola Melhor, Vida Melhor. Ceará - 2003/2006. Fortaleza: Secretaria da Educação Básica do Ceará, 2004a.

CEARÁ. Governo do Estado do Ceará. Mensagem à Assembleia Legislativa 2004 - Abertura da Sessão Legislativa. Fortaleza: SEPLAG, 2004b.

CEARÁ. Secretaria da Educação Básica. Fundo Estadual de Combate à Pobreza (FECOP) - Área: Educação Básica. Fortaleza, 2004c.

CEARÁ. Governo do Estado do Ceará. Mensagem à Assembleia Legislativa 2005 - Abertura da Sessão Legislativa. Fortaleza: SEPLAG, 2005.

CEARÁ. Secretaria da Educação Básica. Escola melhor, vida melhor: relatório da gestão 2003- 2006. Fortaleza, 2006a.

CEARÁ. Governo do Estado do Ceará. Mensagem à Assembleia Legislativa 2006 - Abertura da Sessão Legislativa. Fortaleza: SEPLAG, 2006b.

COSTA, V. M. F. Federalismo e relações intergovernamentais: implicações para a reforma da educação no Brasil. Educação \& Sociedade, Campinas, v. 31, n. 112, p. 729-748, jul./set. 2010. DOI: $10.1590 /$ S0101-73302010000300005

CURY, C. R. J. Federalismo Político e educacional. In: FERREIRA, N. S. C. (Org.). Políticas públicas e gestão da educação: políticas, fundamentos e análises. Brasília: Liber Livro Editora, 2006. p. 113-129.

CURY, C. R. J. A questão federativa e a educação escolar. In: OLIVEIRA, R. P. de; SANTANA, W. (Orgs.). Educação e federalismo no Brasil: combater as desigualdades, garantir a diversidade. Brasília: UNESCO, 2010. p. 149-167.

CURY, C. R. J. Os desafios da construção de um Sistema Nacional de Educação. Disponível em: <http://conae.mec.gov.br/images/stories/pdf/jamil_cury.pdf>. Acesso em: 07 ago. 2012.

FRANZESE, C. Federalismo Cooperativo no Brasil: da Constituição de 1988 ao sistema de políticas públicas. 2010. 210 f. Tese (Doutorado em Administração Pública e Governo) Escola de Administração de Empresas de São Paulo, São Paulo, 2010.

FREITAS, D. N. T. de. A colaboração federativa e avaliação da educação básica. Revista Retratos da Escola, Brasília, v. 6, n. 10, p. 173-184, jan./jun. 2012.

GATTI, B. A.; BARRETO, E. S. S.; ANDRÉ, M. E. D. A. Políticas docentes no Brasil: um estado da arte. Brasília: UNESCO, 2011.

MORRESI, S. Pactos e política: o modelo lockeano e a ocultação do conflito. In: BORON, A. (Org.). Filosofia política moderna. Buenos Aires: Consejo Latinoamericano de Ciencias Sociales - CLACSO; San Pablo, Departamento de Ciência Política - FFLCH, Universidade de São Paulo, 2006.

RABELO, C. D. Gestão local de políticas: estudo comparativo sobre a condução do PROFA em municípios cearenses. 2010. 225 f. Dissertação (Mestrado Acadêmico em Educação) Universidade Estadual do Ceará, Centro de Educação, Fortaleza, 2010.

RAMOS, J. F. P.; LIRA, L. M.; SOARES, B. I. B. A reforma do Estado e modernização da gestão da educação básica no Ceará (1995-2006). Revista HOLOS, Natal, ano 28, v. 2, p. 261-274, 2012. DOI: $10.15628 /$ holos.2012.880 
SANO, H. Articulação horizontal no federalismo brasileiro: os Conselhos de Secretários Estaduais. 2008. 308 f. Tese (Doutorado em Administração Pública e Governo) - Fundação Getúlio Vargas, Escola de Administração de Empresas de São Paulo, São Paulo, 2008.

WRIGHT, D. S. Para entender las relaciones intergubernamentales: estudio introductorio de José Luiz Méndez. México: Colegio Nacional de Ciencias Políticas y Administración Pública, A. C.; Universidad Autónoma de Colima; Fondo de Cultura Económica, 1997.

Recebido em 30/10/2014

Aceito em 19/06/2015 